\title{
Signaling advertising by multiproduct firms
}

\author{
Cesaltina Pacheco Pires • Margarida Catalão-Lopes
}

Accepted: 27 September 2010 / Published online: 16 April 2011

(C) Springer-Verlag 2011

\begin{abstract}
We consider the use of advertising expenses as quality signals in multiproduct firms, extending previous results on single product firms. In our model, a firm introduces sequentially two products whose qualities are positively correlated. We investigate whether there exist information spillovers from the first to the second market. We show that, when correlation is high, the equilibrium in market 2 depends on the quality reputation the firm has gained in market 1 . Moreover, if a firm with a high-quality product 1 wants to separate from its low-quality counterpart, it needs to advertise more in this market than if the qualities of the two products are unrelated. This advertising level signals not only high quality in the first market, but also the likely quality of the second product. Thus, advertising in the first market has information spillovers in the second market.
\end{abstract}

Keywords Quality signaling · Advertising · Multiproduct firms

JEL Classification $\mathrm{L} 14 \cdot \mathrm{L} 15 \cdot \mathrm{M} 37$

\section{Introduction}

Many firms in real world produce more than one good, and the quality of these goods is often correlated. ${ }^{1}$ However economic literature has mainly dealt with the case of

1 Common examples of this are car producers, soft drink producers, and others.

C. Pacheco Pires $(\varangle)$

CEFAGE-UE, Departamento de Gestão, Universidade de Évora, Largo dos Colegiais,

No. 2, 7000-803 Évora, Portugal

e-mail: cpires@uevora.pt

M. Catalão-Lopes

CEG-IST, Instituto Superior Técnico, Technical University of Lisbon, Lisbon, Portugal 